\title{
The Epidemiological, Clinical, Paraclinical and Prognostic Aspects of Severe Malaria at the Regional Hospital of Thies
}

\author{
Agbogbenkou Tévi Déla-dem Lawson 1*, Madoky Magatte Diop1,2, \\ Viviane Marie Pierre Cisse ${ }^{3}$, Stéphanie Akanni'2, Adama Berthe ${ }^{1,2}$, Papa Souleymane Toure ${ }^{1}$, \\ Bernard Marcel Diop1, Mamadou Mourtalla Ka1 \\ ${ }^{1}$ Department of Health, Thies University, Thies, Senegal \\ ${ }^{2}$ Internal Medicine Department, Thies Regional Hospital Center, Thies, Senegal \\ ${ }^{3}$ Infectious and Tropical Diseases Department, Fann Teaching University Hospital, Dakar, Senegal \\ Email: `lawsalomon@yahoo.fr, maxmadoky@hotmail.com, papatoure@hotmail.fr, bernardmdiop@yahoo.com, mmka@refer.sn
}

How to cite this paper: Lawson, A.T.D., Diop, M.M., Cisse, V.M.P., Akanni, S., Berthe, A., Toure, P.S., Diop, B.M. and Ka, M.M. (2018) The Epidemiological, Clinical, Paraclinical and Prognostic Aspects of Severe Malaria at the Regional Hospital of Thies. Advances in Infectious Diseases, 8, 162-171.

https://doi.org/10.4236/aid.2018.83015

Received: June 14, 2018

Accepted: September 17, 2018

Published: September 20, 2018

Copyright $\odot 2018$ by authors and Scientific Research Publishing Inc. This work is licensed under the Creative Commons Attribution International License (CC BY 4.0).

http://creativecommons.org/licenses/by/4.0/

\begin{abstract}
Introduction: Malaria, the first parasitical endemic disease in the world, is a serious disease with 407,000 deaths in Africa in 2016. It is the main cause of morbidity and mortality in Senegal [1] [2]. Methods: Our retrospective study carried out from $1^{\text {st }}$ January 2010 to 31 December 2013, at the department of internal medicine in the regional hospital of Thies was aimed at studying the epidemiological, clinical, paraclinical and prognostic profile of severe malaria in the autochthonous adults with 15 years and more. Results: Over this 3-year period, 57 patients were hospitalized in 1275 patients due to severe malaria that is to say a hospital prevalence of $4.47 \%$. The average age was 64.21. A clear male predominance has been observed, around 61\% (34/57) against $39 \%(23 / 57)$ with a sex ratio of 1.6. The highest malarial infestation rate was found at the end of the rainy season and at the beginning of the dry season (September to November). The clinical picture which predominates is the neurological affection which represented $33.3 \%$ of the cases. The different aspects of this neurological affection were of coma type, convulsion and prostration in $87 \% ; 21.7 \%$ and $8.6 \%$ respectively. The cerebral malaria was associated or not with other symptoms of severity that are anemia in $41.6 \%$; icterus was represented in $21 \%$ of the cases, cardio-vascular collapse in $15.8 \%$ and hypoglycemia in $5.5 \%$ of the cases. The complications were observed during the hospitalization in $73.6 \%$ of the cases with the type of bacterial pneumonia (47.6\%) and urinary infections $(26.2 \%)$. The curative treatment was based on quinine salts through intravenous track in $100 \%$ of the case with a shift to the Artemisinin combination therapy (ACT) associated with intense care measures. In our study the whole lethality is $17 \%$. Conclusion: The re-
\end{abstract}


sults of our study shows that the severe forms of malaria are still affecting our tropical endemic area, in spite of the prevention efforts made to fight against this plague. This research illustrates the difficulties to provide optimum medical care when combining antimalarial treatment and resuscitative measures in the decentralized reception facilities.

\section{Keywords}

Malaria, Severe Malaria, Quinine, ACT

\section{Introduction}

Paludism or malaria is the first parasitical endemic disease in the world. It is a serious disease because of its deadly forms due to Plasmodium falciparum, vivax and knowlesis [1]. According to WHO, around $40 \%$ of the world population living in the poorest countries is exposed to malaria, with 198 million cases in 2014 and 584,000 deaths among them. Africa is affected with $82 \%$ of the malaria cases and $90 \%$ of the dead cases occur there [1]. However, WHO reports that there is a decreasing of $47 \%$ of the malaria cases throughout the world and of $54 \%$ in the African region [1] [2]. In Senegal, malaria represents 35\% of the motives for consultation. In 2014, the number of confirmed malaria cases was 265,624 and 12,636 among them were serious cases, that is to say $4.7 \%$ of the cases. In Senegal, a lot of studies were carried out on the simple forms, but very little on serious malaria. Most of the studies on the serious forms of malaria were conducted in the region of Dakar (The capital city of Senegal) which presents an epidemiological faces different. A description of the serious forms in the other regions is important to the current context of pre-elimination. This is the reason why this study was conducted in the city of Thies $70 \mathrm{~km}$ away from the capital city in order to improve the medical care of patients admitted to the decentralized hospitals.

\section{Methodology}

This was a retrospective study, started from $1^{\text {st }}$ January 2010 to $31^{\text {st }}$ December 2013 upon medical reports of patients suffering from malaria, and admitted at the department of internal medicine in the regional hospital of Thies.

The study included both male and female patients who were more than 15 years and admitted at the intensive unit for severe malaria. The diagnosis for severe malaria was used according to the 2000 definition criteria of WHO, such as: the presence of asexual forms of Plasmodium falciparum in the thick smear and thin smear associated to one or several of the 14 criteria of severity by WHO.

Patients who did not undergo "Goutte Epaisse" (Detection parasites when examining under the microscope blood smear) as well as pregnant, breastfeeding women and children of 0 to 14 years and the suspicious cases of severe malaria 
which were not confirmed by a parasitological examination were not included.

A data collection form had allowed us to gather the socio-demographic data (age, sex, geographical origins, years, months) and the clinical data (temperature, state of consciousness, presence of convulsion, jaundice, collapse, kidney failure, anemia as well as the level of hemoglobin).

The descriptive study consisted in calculating the frequencies for the qualitative variables and the averages for the quantitative variables. The analytical study had allowed us to cross-check some independent variables with the dependent variable (occurrence of deaths).

Data entry and analysis were made using version 3.5.4 EPI-INFO software. Averages and percentages were compared with the aid of Chi2 test and of Fisher test in accordance with their conditions of applicability.

\section{Results}

\subsection{General Data}

From $1^{\text {st }}$ January 2013 to $31^{\text {st }}$ December 2013, the department of internal medicine at the regional hospital of Thies had received 1275 patients who were admitted and 57 among them suffered from severe malaria according to the definition of WHO, that is to say a hospital prevalence of $4.4 \%$.

The analysis of the monthly incidences reveals a progressive increase of malaria cases from August, reaching a peak in October (8 cases representing 14\%) and in November (10 cases representing 17, 5\%). The correlation with the meteorological data shows that most of the severe malaria cases occur during and particularly at the end of the rainy season in Senegal (see Figure 1).

The average age of the population for our study was $40.9 \pm 23$ years. The median was 29 years [15 - 95 years]. The most affected age group ranged between 15 - 30 years $(60 \%)$.

We made a list of 35 men (61\%) for 22 women (39\%) that is to say a sex ratio of 1.6.

\subsection{The Clinical View}

Underlying chronic pathologies were identified in 9 patients (16\%), dominated by High Blood Pressure ( 3 cases), diabetes ( 3 cases) and stroke.

The neurological affection represented $33.3 \%$ of the cases. The different aspects of this neurological affection were of coma type, convulsion and prostration in $87 \% ; 21.7 \%$ and $8.6 \%$ respectively. The coma was vigil in $79 \%$ of the cases and carus in $21 \%$ of the cases.

Icterus was represented in $21 \%$ of the cases, cardiovascular collapse in $15.8 \%$ and pulmonary edema in $8.8 \%$. The abnormal bleeding (3.5\%) and hemoglobinuria $(1.7 \%)$ were slightly represented. The clinical signs of severity are summarized in Table 1.

The main complications were the pneumonia with 18 cases $(31.5 \%)$ and the septicemia with 4 cases (7\%). 


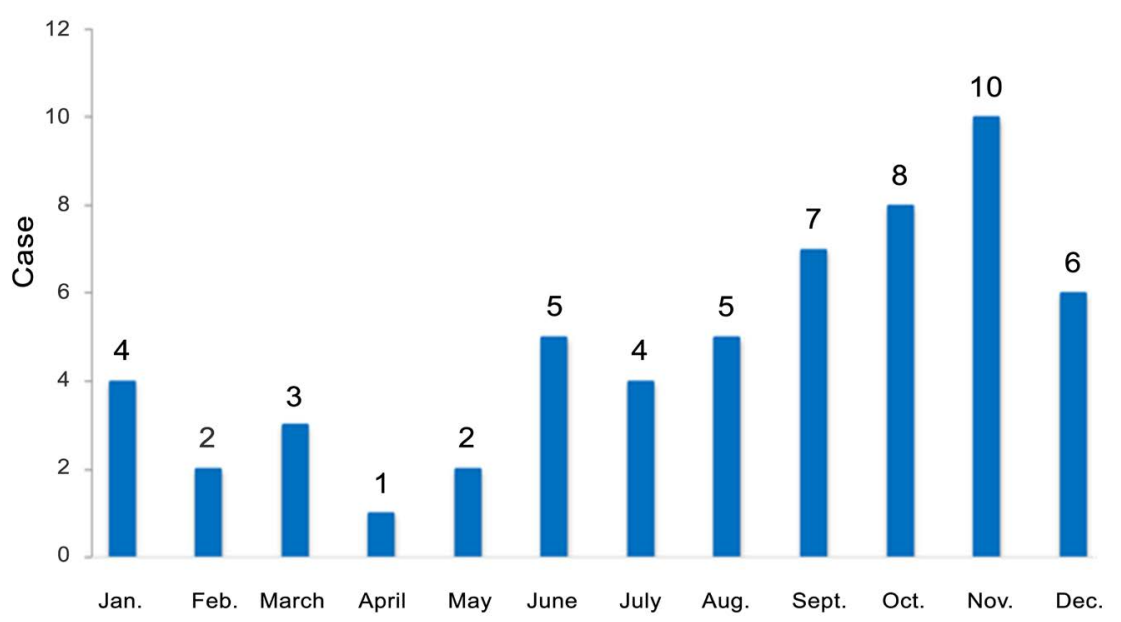

Figure 1. Monthly distribution of cases of severe malaria.

Table 1. Distribution of severe malaria cases by frequency of clinical signs of severity.

\begin{tabular}{ccc}
\hline Clinical signs & Number of cases & Percentage (\%) \\
\hline Coma & 19 & 33.3 \\
Convulsions & 5 & 8.8 \\
Prostration & 8 & 14 \\
Icterus & 12 & 21 \\
Cardiovascular collapse & 9 & 15.8 \\
Abnormal bleeding & 2 & 3.5 \\
Pulmonary edema & 5 & 8.8 \\
Hemoglobinuria & 1 & 1.7 \\
Acidic respiration & 0 & 0 \\
\hline
\end{tabular}

\subsection{The Paraclinic View}

Forty-seven patients underwent a blood count test and the average level of hemoglobin was $10.35 \mathrm{~g} / \mathrm{dl} \pm 2.28 \mathrm{~g} / \mathrm{dl}$.

The average ratio of platelet was 135,665.8 $\pm 121,595.4$ elements $/ \mathrm{mm}^{3}$.

The quantitative analysis of the glycaemia was carried out in 29 patients. The average glycaemia was $1.08 \pm 0.55 \mathrm{~g} / \mathrm{l}$ with extremes of 0.2 and $2.9 \mathrm{~g} / \mathrm{l}$.

The quantitative analysis of the creatinine in the blood was carried out in 28 patients. The average serum creatinine was $16.16 \mathrm{mg} / 1 \pm 27.38$ with extremes of $5.7-144 \mathrm{mg} / \mathrm{l}$.

The CRP was made in 13 patients and the median was $24 \mathrm{mg} / \mathrm{l}$ with extremes of 6 and $384 \mathrm{mg} / \mathrm{l}$. Concerning the biological symptoms of severity found, severe anemia with an hemoglobin level $<5 \mathrm{~g} / \mathrm{dl}$ was found in 3 patients. Two patients showed a serum creatinine $>30 \mathrm{mg} / \mathrm{l}$ and two others, a sever hypoglycemia with a fasting glycaemia $<2.2 \mathrm{mmol}$ or $0.4 \mathrm{~g} / \mathrm{l}$.

\subsection{The Treatment View}

All the patients had taken quinine salts through the indications for use of 
$25 \mathrm{mg} / \mathrm{kg} /$ day administered by infusion for four (4) hours with intervals of eight (8) hours.

A shift to oral route followed after with the use of ACT (Dihydroartemisinin-Piperaquine in $97 \%$ and artemether-lumefantrine in $3 \%$ of the cases)

\subsection{The Progressive View}

The average time of hospitalization was $5.08 \pm 1.74$ days. More than half of the population studied, for instance 31 cases had stayed at hospital for 4 to 6 days.

Complications were noticed in $73.6 \%$ of the cases that is to say in 42 patients. Then, pneumonia and urinary tract infections were the most observed with $47.6 \%(20 / 42)$ and $26.2 \%(11 / 42)$ respectively.

The progress was favorable in 46 patients ( $81 \%$ of the cases). One patient was transferred to the nephrology department. The lethality was $18 \%$.

The number of deaths is more important in patients suffering from neurological disorders with $33.3 \%$ of lethality. Patients with anemia come next in the second position with $29.4 \%$ of the cases followed by those with an icterus in $20 \%$. 2 deaths represented $9.2 \%$ for the cardiovascular collapse. The anemia with a hemoglobin level between 5 and $6 \mathrm{~g} / \mathrm{dl}$ showed the highest level of lethality (25\%).

\section{Discussion}

\subsection{General Data}

For a period of 3 years, the hospital prevalence of the severe malaria was $4.47 \%$ at the regional hospital of Thies. This rate is lower than the results reported in Dakar (12.39\%) [1] and Ziguinchor (19.9\%) [2].

Furthermore, these data are stackable to those of Diallo [3], in Burkina Faso, who had identified 60 severe malaria cases for a period of 10 months. In the West-African region, with the Sudano-Sahelian climate type, a decline of the rainfall has been noticed since 2008 with annual average rainfall which are in the order of 300 to $500 \mathrm{~mm}$ that can explain this difference compared to the other African regions. In Senegal, the rainfall difference between the north with a Sudano-Sahelian climate and the south with a tropical climate leads to a large variation of prevalence between Thies and Ziguinchor, as Thies is also an area of low malaria transmission.

A peak of frequency was noticed during October (8 cases) and November (10 cases). This result is similar to most of the studies conducted in Senegal [1] [2] [4]. Most of the transmission occurs in that period which is favorable to the development of the carrier species corresponding to the post rainy season. These results remain in line with the previous studies of Gaye [5] who mentioned that malaria is generally endemic in Senegal with a new outbreak of the transmission during the rainy season which lasts from June to October.

The average age of 40.9 years \pm 23 years found in our series was close to the one of Dièye (38.5 years \pm 20.94 years) [1] and was slightly superior to the one 
reported by Ndiaye (33.3 years \pm 18.06 years [2]. Rakotoarivelo [6] in Madagascar and Charra [7] in Morocco had pointed out an average age of 32 and 35 years respectively.

These results lead us to state that the risk to catch the severe malaria is higher in the young adults. This can be explained by the existence of a slight premonition within the adult population which is in those areas of low transmission.

The male predominance $(61.4 \%)$ noticed in our series is comparable to the one of Dièye [1] who had colligated a percentage of $68 \%$.

\subsection{The Clinical View}

In our series, nine patients presented an underlying defect. Those defects were dominated by high blood pressure and diabetes. Dièye [1] had found again that predominance of the high blood pressure. Those patients with delicate conditions should take advantage of a strict observation because Plasmodium falciparum has more damaging effects on these vulnerable populations [8].

The clinical pictures observed in our series were close to those of the pernicious access of the child during which the neurological affection is most of the time at the forefront and represented 24 cases in our series that is to say (42\%). These results confirm those from other studies conducted on severe malaria in Senegal and in the sub-region. Diop SA [4] had identified this predominance of neurological symptoms (76.8\%). Savadogo [9] had found that the neurological symptoms represented $46 \%$ of the cases both in the adult and the child.

Among the patients to whom consciousness disorders were found, the majority presented a vigil coma (79\%). Those results are similar to the data of Ndiaye [2].

Moreover, Kempff [10] had pointed out that consciousness disorders were often limited to a $70 \%$ obnubilation against $30 \%$ for the deep coma. On the contrary, Eholie had identified a predominance of the deep coma (66\%) on his study conducted in Ivory Coast [11].

Icterus came as the second position in our series with $21 \%$ stackable to the results of Belguiti [12] and Dieye [1] who had compiled a ratio of $24.4 \%$ and $28 \%$ respectively.

Besides, in our context self-medication through herbal medicine might explain the highest frequency of this symptom.

A circulatory collapse or a state of shock producing the classic «algid malaria», was present in $15.8 \%$ of the cases. Brunel F and al [13] had found a prevalence of $22 \%$. The pathogeny of these circulatory disorders is discussed involving hypovolemia and the plasmodial toxins.

The respiratory symptomatology would often come down to a picture of bronchial congestion in a patient presenting consciousness disorders. A hypoxemia with $\mathrm{Pa} 02<60 \mathrm{mmhg}$ is frequent, associated with an interstitial radiological syndrome. It is the transformation into an interstitial pulmonary oedema. This pulmonary oedema often appears after starting the treatment. This clinical 
particularity is classically explained by an extreme initial filling. In our series 5 patients had presented a pulmonary oedema.

Moreover, $31 \%$ of the patients presented a pneumonia during the progress. Charra, in a study conducted in Morocco [7] on the introduction of malaria, all the patients presented a nosocomial pneumonia which was mainly caused by the gram-negative bacillus. During severe malaria, the lung is particularly delicate and a lot of factors participate to the hypoxaemia: lesion oedema induced by the parasite, excess of filling up when there is a shock, excessive sodium provision when there is anuria, inhalation or bacterial pneumonia, lesion oedema associated with a bacteraemia. The co-infection of severe malaria and bacterial pneumonia was described by several other researchers [7] [14].

\subsection{The Paraclinic View}

The Plasmodium falciparum was the only plasmodial species responsible for severe malaria. However, a lot of recent studies identified Plasmodium vivax and Plasmodium knowlesi in patients presenting severe forms of malaria [1] [13].

From studies conducted in India, [15] and in Pakistan [8], the researchers reported mixed forms due to Plasmodium falciparum and vivax, hence the need to carry out systematically the blood smear for the diagnosis of species.

The average level of hemoglobin was $10.35 \mathrm{~g} / \mathrm{dl} \pm 2.28 \mathrm{~g} / \mathrm{dl}$ and 3 patients had showed a severe anemia. This is stackable to the results of Diop [4] and Belgui [12] who found $10 \mathrm{~g} / \mathrm{dl}$ and $9.87 \mathrm{~g} / \mathrm{dl}$ respectively. That anemia is necessary during the severe malaria explained by a haemolysis and a bad medullary regeneration [1]. Besides, anemia causes a transfer of insufficient oxygen at the level of the cerebral tissue; thereupon causes the cerebral hypoxia which worsens a shaky and neurological state.

Thrombocytopenia is an element which helps for the diagnosis of malaria [4] [11] [16]. It is a common haematological modification on malaria, which can be the fact of the peripheral destruction plaquetaire and the consumption. Its mechanisms are numerous: intravascular lysis, reduction of the lifespan plaquetaire, splenomegaly, and reduction of the medullary production and sequestration in the vessel in contact of the parasitized red blood corpuscles. In his study, Sawsan had detected a thrombocytopenia in $42.9 \%$ of the patients suffering from severe malaria [17]. The thrombocytopenia, especially the severe one, constituted therefore an important prognostic element and the risk to present severe malaria was increased [4] [17].

The quantitative analysis of the creatinine in the blood, was carried out in 28 patients and two among them presented a serum creatinine higher than $30 \mathrm{mg} / \mathrm{l}$. The kidney failure during malaria is a matter for several mechanisms. It can be a manifestation of shock at the level of the kidney if there is a circulatory failure, but also the fact of the precipitation of hemoglobin crystals in the kidney tubules during an intravascular hemolysis. Finally, in case of strong parasitaemia, anoxo-ischaemic lesions can be observed in connection with phenomenon of cytoad- 
herence of the trophozoite at the level of the endothelium of the kidney capillaries. [12].

Hypoglycaemia is rare in the adult as it is confirmed by our study $3.5 \%(2 / 57)$ of the cases. We must consider the situation when the consciousness state suddenly worsens, secondarily after the quinine treatment. All in all, this criterion should be probably kept in the definition of the adult mainly because of its therapeutic implications. [7] [11].

The CRP was done in 13 patients with an average of $59 \mathrm{~g} / \mathrm{ml}$. A CRP $>12 \mathrm{mg} / \mathrm{l}$ was found in some cases. The CRP is a protein of the interest inflammation in the diagnosis of the bacterial infections; however, its raising was described during malaria caused by Plasmodium falciparum. It was difficult to distinguish things.

\subsection{The Therapeutic and Progressive Aspects}

Quinine was the only anti-malarial drug used through injection. Since 2015, Artesunate IV has been introduced for the treatment of the 2005 severe malaria [1] [2]. Artesunate leads to the shortening of the stay at hospital but also reduce the death rate [15]. From its enacted recommendations in 2014, WHO recommended to use injectable Artesunate as the first-line treatment against severe malaria, which was adopted by Senegal in 2016 [2].

The frequency of the bacterial co-infections during severe malaria can explain the use of antibiotics in our series. It can be both community and hospital-acquired bacterial infections [14]. However, any bacterial proof was found in our studies. This suspicious just rested on the clinic and the paraclinical elements of presumption such as a hyperleukocytosis and an increase of the CRP.

The lethality of $18 \%$ reported in our series confirms the data of other studies, conducted in Dakar [1] [4] and in the sub-region [9] [11].

The number of deaths is more important in the patients suffering from neurological disorders with $33.3 \%$ of lethality. Patients suffering from anemia come as the second position with $29.4 \%$ of the cases followed by those with icterus in 20\%. 2 deaths represented $9.2 \%$ for cardiovascular collapse. The anemic patients with a hemoglobin level between 5 and $6 \mathrm{~g} / \mathrm{dl}$ showed the highest level of lethality $25 \%$. These results are comparable to those of Eholie [11] observed in Ivory Coast.

\section{Conclusion}

Malaria remains a worrying disease which is being rife in the intertropical area of the African continent. Severe malaria of the adult is still a reality in endemic disease areas. This therapeutic emergency depends on several factors of which the most essentials are urbanization and rainfall. This research brings out the importance of the adjuvant measures when taking care of the multi various failures observed in the severe forms of malaria which are often connected to other infectious or non occurring pathologies: decentralized hospital institutions 
should be equipped in an appropriate way with emergency and intensive care materials. However, the retrospective nature of our study requires conducting a prospective multicentre research on severe malaria in decentralized areas while taking into consideration the clinical, entomological, immunological data and the resistance of Plasmodium.

\section{Conflicts of Interest}

The authors declare no conflicts of interest regarding the publication of this paper.

\section{References}

[1] Dièye, A. (2014) Paludisme grave et Infections bactériennes associées au Service des Maladies Infectieuses du CHUN de Fann: Aspects épidémiologiques, cliniques, paracliniques et évolutifs. Thèse Méd, Dakar, 201.

[2] Ndiaye, F. (2016) Aspects épidémiologiques, cliniques, paracliniques et évolutifs du paludisme grave chez l'adulte au Centre de Santé Silence à Ziguinchor. Thèse Méd, Dakar, 50.

[3] Diallo, A.H., Ki-Zerbo, G., Sawadogo, A.B., et al. (2014) Paludisme grave et infection à VIH chez l'adulte à Bobo-Dioulasso, Burkina Faso. Médecine Tropicale, 64, 345-350.

[4] Diop, S.A, Ndour, C.T, Bâ, N.M., et al. (2010) Aspects actuels du paludisme grave de l'adulte à la clinique des maladies infectieuses du CHNU de Fann de Dakar (Sénégal). Médecine Afrique Noire, 57, 193-197.

[5] Gaye, O., Bengua, E., Diallo. S., et al. (1989) Morbidité palustre en milieu rural et urbain au Sénégal. Médecine Tropicale, 49, 59-62.

[6] Rakotoarivelo, R.A., Raveloson, H.F.R., et al. (2009) Aspects cliniques et thérapeutiques du paludisme grave de l'adulte en milieu hospitalier à Antananarivo, Madagascar. Bulletin de la Société de Pathologie Exotique, 102, 215-216.

[7] Charra, B., Sodqi, M., Sandali, O. et al. (2007) Paludisme grave d'importation chez l'adulte: étude rétrospective de dix cas admis en réanimation à Casablanca. Médecine et Maladies Infectieuses, 37, 162-165. https://doi.org/10.1016/j.medmal.2006.09.006

[8] Gupta, B.K., Gupta, A., et al. (2015) Clinical Profile and Prognostic Indicators in Adults Hospitalized with Severe Malaria Caused by Different Plasmodium Species. Infectious Diseases (Auckl), 8, 45-50. https://doi.org/10.4137/IDRT.S34039

[9] Sawadogo, M., Ouédraogo, A., Sondo, K.A., et al. (2014) Aspects épidémiologiques,cliniques et thérapeutiques du paludisme au CHU Yalgado Ouédraogo de Ouagadougou, Burkina Faso. Médecine Afrique Noire, 61, 374-378.

[10] Kempf, J., Diatta, B., Vitris, M., et al. (1994) Severe Malaria in African Adults Living in a Seasonal Endemic Area. Intensive Care Medicine, 20, 437-441. https://doi.org/10.1007/BF01710655

[11] Eholié, S.P, Ehui, E., Adou-Bryn, K., et al. (2004) Paludisme grave de l'adulte autochtone à Abidjan (Cote d'Ivoire). Bulletin de la Société de Pathologie Exotique, 97, 340-344.

[12] Belguiti Alaoui, H. (2011) Paludisme grave de l'adulte: Aspects épidémiologiques, cliniques, para cliniques et évolutifs à propos de 381 cas à la clinique des maladies infectieuses du CNHU de Fann. These Méd Dakar, 56. 
[13] Bruneel, F. (2011) Paludisme grave d'importation. Journal des Anti-infectieux, 13, 39-48. https://doi.org/10.1016/j.antinf.2010.12.001

[14] English, M., Punt, J., Mwangi, I., et al. (1996) Clinical Overlap between Malaria and Severe Pneumonia in Africa Children in Hospital. Transactions of the Royal Society of Tropical Medicine and Hygiene, 90, 658-662. https://doi.org/10.1016/S0035-9203(96)90423-X

[15] Imran, R., Devendra Kumar, T., Anjum Mirza, C., et al. (2013) Complications Associated with Plasmodium vivax Malaria: A Retrospective Study from a Tertiary Care Hospital Based in Western Uttar Pradesh. India Annals of African Medicine, 12, 155-159. https://doi.org/10.4103/1596-3519.117624

[16] Imtiaz, S., Drohlio, M.F., Nassir, K., et al. (2015) Morbidity and Mortality Associated with Plasmodium vivax and Plasmodium falciparum Infection in a Tertiary Care Kidney. Saudi Journal of Kidney Disease and Transplantation, 26, 1169-1176.

[17] Sawsan, B. (2013) Hematological Parameters in Severe Complicated Plasmodium falciparum Malaria among Adults in Aden. Turkish Journal of Hematology, 30, 394-399. https://doi.org/10.4274/Tjh.2012.0086 